\title{
Reservoir Characteristics and Its Comprehensive Evaluation of Gray Relational Analysis on the Western Sulige Gas Field, Ordos Basin, China
}

\author{
Xinping Liang $\mathbb{D}^{1,2}$ Qingbin Xie, ${ }^{3}$ Mingyu He, ${ }^{4}$ Quanyou Liu, ${ }^{2}$ and Vladimir Morozov ${ }^{5}$ \\ ${ }^{1}$ Institute of Energy, Peking University, Beijing 100871, China \\ ${ }^{2}$ State Key Laboratory of Shale Oil and Gas Enrichment Mechanisms and Effective Development, SINOPEC Exploration and \\ Production Research Institute, Beijing 100083, China \\ ${ }^{3}$ College of Geosciences, China University of Petroleum (Beijing), Beijing 102249, China \\ ${ }^{4}$ Faculty of Geology and Geophysics, National University of Oil and Gas Gubkin University, Moscow 119991, Russia \\ ${ }^{5}$ Institute of Geology and Petroleum Technologies, Kazan Federal University, Kazan 420008, Russia \\ Correspondence should be addressed to Xinping Liang; xinping.liang@pku.edu.cn
}

Received 22 November 2020; Revised 15 December 2020; Accepted 4 January 2021; Published 18 January 2021

Academic Editor: Jinze Xu

Copyright (c) 2021 Xinping Liang et al. This is an open access article distributed under the Creative Commons Attribution License, which permits unrestricted use, distribution, and reproduction in any medium, provided the original work is properly cited.

\begin{abstract}
Although the Sulige gas field has been developed for several years, accurate reservoir classification, evaluation, and prediction is still a worth-exploring scientific issue as this is a necessary procedure which could give the guidance of well deployment during later gas field development. Here, based on the analysis of lithological features and diagenesis, we give an evaluation of gas reservoirs in the western Sulige gas field by using the improved method of gray relational analysis. Our results show that the study area Su- 54 block is dominated by low permeability and low porosity litharenite and lithic silicarenite with clear evidence of strong diagenesis processes. Compaction is believed to be relatively strong due to the great burial depth and destroy most of the primary pores. Based on the premise of a lower limit of an effective reservoir, we select five parameters (permeability $(K)$, porosity $(\Phi)$, effective sand thickness $(M)$, effective sand/sand thickness ratio $(D)$, and gas saturation $\left(S_{\mathrm{g}}\right)$ ) to calculate the correlation coefficient, relational degree, and index weights for reservoir quality evaluation. By weighted gray correlation theory, the dynamic testing data-effective thickness of gas production data-is used as mother sequences. The results show that the predicted favorable areas for gas exploration and development coincide well with sedimentary and sand body distribution (e.g., point bars and central bars) in the study block; well blocks such as s372, s373, s374, and e24 could be future key development targets. This also indicates a broader application of the gray relational analysis to quality evaluation and distribution prediction of reservoirs. Therefore, our findings could give a new theoretical and practical guidance for the later gas exploration and development, for the search of hidden stratigraphic lithological traps, and for the improvement of the proven rate of oil and gas resources in this area.
\end{abstract}

\section{Introduction}

With recent improvements in oil and gas exploration, the prediction and evaluation of exploration areas are becoming increasingly important, especially in unconventional tight reservoirs [1-6]. In addition to providing the necessary geological information on reservoirs, the prediction of potential exploration areas may be used to accurately and comprehensively understand reservoir characteristics. It may also be conducive to developing programs and be adjusted to the development process as well as dynamic data analysis and summary. At present, conventional qualitative analysis has been gradually transformed into part quantitative reservoir evaluation $[1,6-9]$.

Reservoir oil and gas-bearing properties are important indicators for predicting the distribution of petroliferous areas. However, it is always complicated for an effective and reasonable reservoir interpretation by using the existing data due to individual factors and other uncertainties during the evaluation process. Data obtained by subjective geophysical 
interpretation lacks reliability as it performs poorly in recognizing the effect on low permeability reservoirs with low resistance and thin layers. Gray relational analysis of reservoir parameters is used to find key relationships between parameters through certain methods in reservoir evaluation [10-13]. This identifies important factors which affect the reservoir, helping to accurately grasp the main parameters in evaluating reservoir characteristics. This analytical method quantitatively describes and compares the development trends in the reservoir evaluation system. It is the basis of gray system analysis and forecasting. Gray correlation analysis includes the mother sequence and subsequence selection, raw data transformation, correlation coefficients, and correlation degree calculation [13-15].

Although Su-54 block has been developed since 2011, accurate reservoir classification, evaluation, and prediction is still a worth-exploring scientific issue and could give a guide of well deployment during the gas field development. Previous studies on the western Sulige gas field are mostly focused on the overall geological reservoir characteristics, including porosity, permeability, gas filling patterns, and main controlling factors for the distribution of high-quality reservoirs [16-24]. Here, based on general geological characteristics (such as tectonic background and stratigraphic characteristics), lithological features, diagenesis, and other reservoir physical characteristics of the whole area, we give a comprehensive evaluation after selecting five parameters: permeability $(K)$, porosity $(\Phi)$, effective sand thickness $(M)$, effective sand and sand thickness ratio $(D)$, and gas saturation $\left(S_{\mathrm{g}}\right)$. Of these parameters, the effective thickness of gas production data is used as the mother sequence because it reflects the reserve abundance. Then, we transform the original data to calculate the correlation coefficient, relational degree, and index weights for the classified reservoir. Finally, the relatively independent reservoir is selected, and the potential gas areas in He- 8 member $\left(\mathrm{P}_{2} \operatorname{sh} \mathrm{h}_{8}\right)$ and Shan-1 member $\left(\mathrm{P}_{1} s_{1}\right)$ are forecasted for further exploration and deployment.

\section{Geological Setting}

The Sulige gas field is located in the Ordos Basin on the northwest edge of the Yishan Slope. It stretches across the Yimeng Uplift and Tianhuan Depression, administratively subordinate to Ordos City in the Inner Mongolia Autonomous Region, China. The total exploration area of the field is approximately $3.6 \times 10^{4} \mathrm{~km}^{2}[16,21]$. It is a very large land gas field in China. In the study area of Su-54 block, the overall structure shows a gently sloped monoclinic from northeast to southwest. Zone faults and arched structures are not so developed, except for a wide-gentle slope existing at a lowgentle nose structure from the northeast towards the southwest. The amplitude of the structure is small, averaging $3.84 \mathrm{~m} / \mathrm{km}^{2}$. The maximum buried depth of the structure is about $4000 \mathrm{~m}$. The main gas-bearing bed in the gas field is the He-8 member $\left(\mathrm{P}_{2} s h \mathrm{~h}_{8}\right)$ in the Lower Shihezi Formation $\left(\mathrm{P}_{2} s h\right)$ and the Shan-1 member $\left(\mathrm{P}_{1} s_{1}\right)$ in the Shanxi Formation $\left(\mathrm{P}_{1} s\right)$ in Permian in Upper Paleozoic [16, 19$21,25])$. Gas layers are compositely superimposed by multi- ple single sand bodies, and buried at depths ranging between 3200-3500 m with a thickness between 80-100 m. They contain a gas reservoir with low porosity, low permeability, and low abundance of large lithology traps ([21]; Liu et al., [18, 26, 27]).

The study area is located on the west of the Sulige gas field, structurally on the border of the Yishan Slope, Yimeng Uplift, and Tianhuan Depression. The exploration area of the block is approximately $2800 \mathrm{~km}^{2}$ (Figure $1(\mathrm{a})$ ). The Lower Shihezi Formation is approximately $140-160 \mathrm{~m}$, conformably overlies the Shanxi Formation, and is overlain conformably by the Upper Shihezi Formation (Figure 1(b)). The sedimentary facies of the Shihezi Formation in the Ordos Basin have been well studied; previous research indicated that sandstones in river channels are the main deposits in Lower Shihezi Formation, and therefore, it is the predominant potential reservoir $[16,20,21]$. Our previous studies by core analysis and well log data also suggested that different types of channel deposits were developed in the Lower Shihezi Formation in the research area (Figure 1(c)).

\section{Reservoir Characteristics}

3.1. Lithological Features. The main gas-bearing layers are He- $8\left(\mathrm{P}_{2} s h \mathrm{~h}_{8}\right)$ and Shan-1 members $\left(\mathrm{P}_{1} s_{1}\right)$ in the Permian of Upper Paleozoic in the study area. Cores and thin section studies show that the main types of reservoir rocks are litharenite and lithic silicarenite. The main rock types of the He-8 member are dominated by litharenite and lithic silicarenite with a small amount of silicarenite. The Shan-1 member $\left(\mathrm{P}_{1} s_{1}\right)$ consists of only litharenite and lithic silicarenite. In the upper $\mathrm{P}_{2} s h \mathrm{~h}_{8}$ and $\mathrm{P}_{1} s_{1}$ members, there are relatively well-developed fine clastic rocks; sometimes, coal seams could be seen in $\mathrm{P}_{1} s_{1}$. The conglomerate of $\mathrm{P}_{2}$ shh $\mathrm{h}_{8}$ is compound, and the gravel is mainly various metamorphic rocks, such as quartzite, phyllite, gneiss, slate, and metamorphic sandstone. The clastic components of sandstone are mainly quartz and lithic debris, and the average content of feldspar does not exceed $0.3 \%$. It is dominated by lithic sandstone; lithic quartz sandstone and quartz sandstone are rarely seen. On the whole, the composition of debris is relatively complicated with quartz, chert, quartzite debris, feldspar, and lithic components. The lithic debris mainly consists of tuff, schist, phyllite, and slate. The volume of quartz debris is relatively high, while that of lithic debris is relatively low.

The granularity of sandstone in the study intervals is generally crude with a size range of $0.25-2.05 \mathrm{~mm}$. Coarse sandstone and medium sandstone dominate the study area. The separation of grains is from medium to good and has subedged and subrounded shapes. Most of the contact types between granules are liner and point-liner contact. This indicates that sandstones were strongly influenced by compaction, which was relatively strong due to the deep burial of reservoir rocks underground. The rock particles of $\mathrm{P}_{1} s_{1}$ are finer than that of $\mathrm{P}_{2} s h \mathrm{~h}_{8}$, the content of coarse sandstone and conglomerate components are reduced, and the fine sandstone grade components are relatively increased, indicating a longer transport distance. The granularity data of the study area reflects the characteristics of traction flow. 


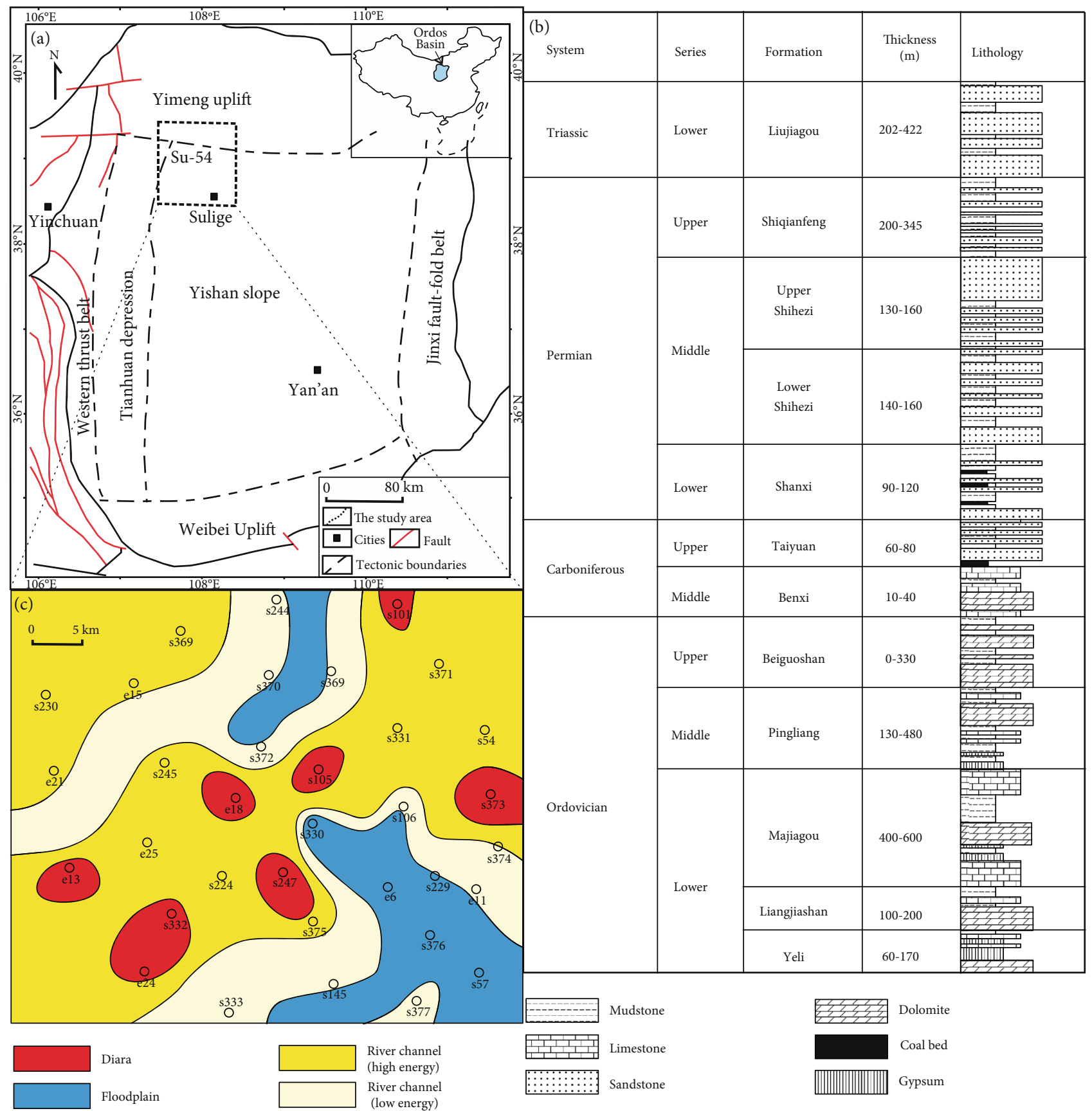

FIGURE 1: (a) Structural location of the study area in the western Sulige gas field (modified from Xie et al. [19]), (b) stratigraphic column from the Ordovician Majiagou Formation to the Triassic Liujiagou Formation in the northern Ordos Basin (modified from [28, 29]), and (c) sedimentary facies of $\mathrm{P}_{2} s h \mathrm{~h}_{8}{ }^{2}$ in the Su-54 block.

On the plane, the composition and structural maturity of reservoir rocks show a gradually improving trend from north to south. The cement of sandstone is mainly composed of siliceous, clay mineral, carbonate, and tuffaceous material. Grain-supported pore-space filling is the dominant cementation type of reservoir rocks.

All the above comprehensive analysis indicates various sedimentary facies in the study block: an anastomosing river in $\mathrm{P}_{1} s_{1}$, braided river in the lower of $\mathrm{P}_{2} s h \mathrm{~h}_{8}$, and a meandering and anastomosing river in the upper $\mathrm{P}_{2} s h \mathrm{~h}_{8}([19,20])$. In
$\mathrm{P}_{1} s_{1}$, the anastomosing river has developed a dual structure. At the bottom, it is riverbed detainment with sedimentation of an eroding surface. In the upper section are levees, with wetlands at the point or central bars. The dual structure bottom coarse sediments are well developed. The river does not flood, and vertical rhythm is often incomplete, manifesting typically as sand encircling mud. In the $\mathrm{P}_{2} s h \mathrm{~h}_{8}{ }^{2}$ layer, the braided river transits to a meandering river and finally evolves to an anastomosing river in the $\mathrm{P}_{2} \operatorname{shh}_{8}{ }^{1}$ layer (Figure 2). 


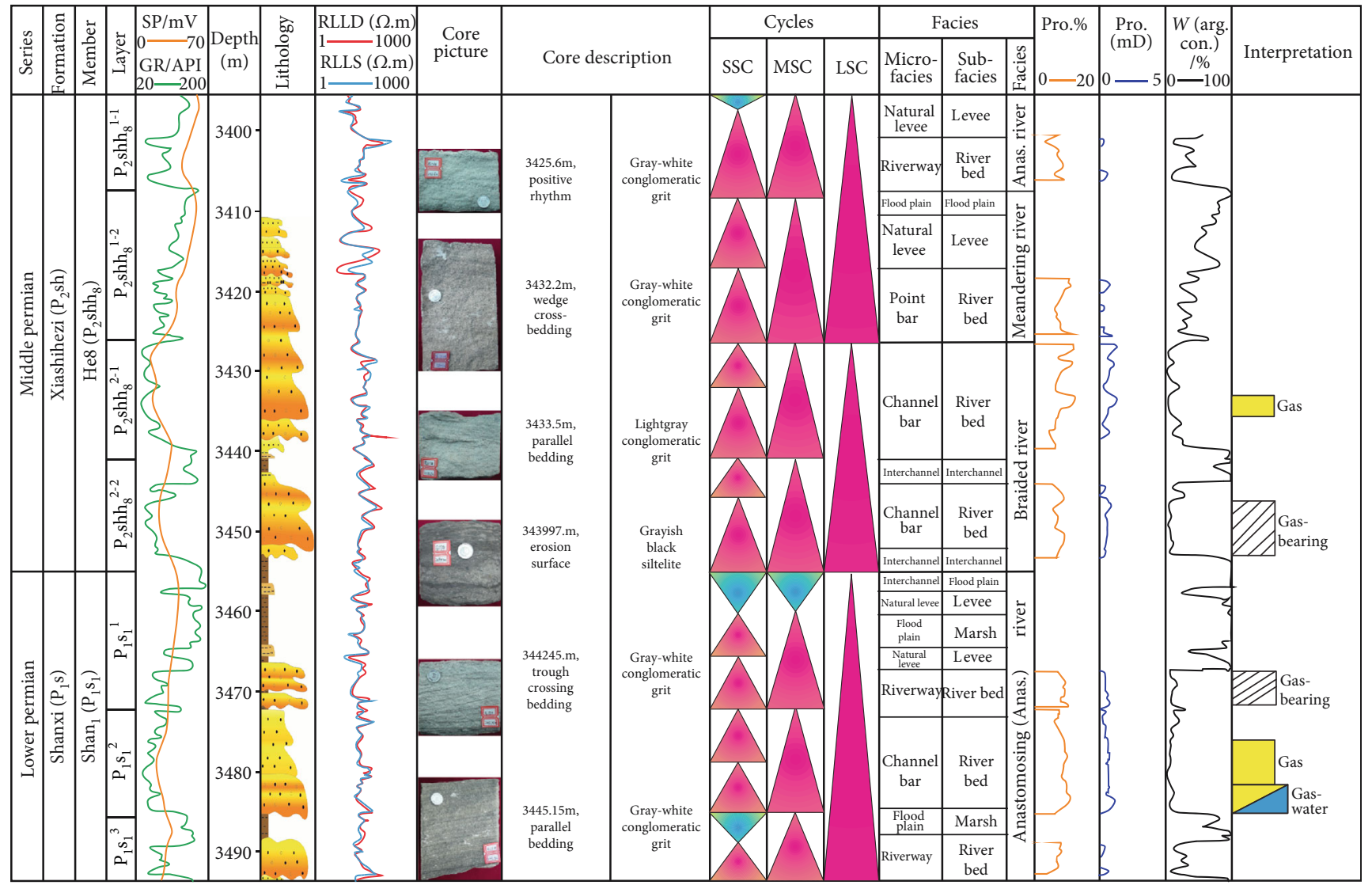

FIGURE 2: Sequence stratigraphy and core analysis of Well s373 in the western Sulige gas field.

3.2. Diagenesis. The study of diagenesis in the Su-54 block is based on the analysis of thin sections of reservoir rocks. The main diagenesis in the study area includes compaction, cementation, dissolution, metasomatism, and rupture. Among them, compaction, cementation, and dissolution have a relatively greater influence on reservoir properties. The digenetic evolution of the Upper Paleozoic reservoir rocks in the Ordos Basin experienced two important stages. The first stage was between the Carboniferous and Triassic, and the second stage was during the Jurassic. During these stages, reservoir rocks experienced fast compaction and siliceous cementation [16, 30-32].

Compared with most formations in the Sulige gas field, the main gas-bearing formations in the Su-54 block have greater burial depth (3347-3805 m). Thus, compaction strongly influenced reservoir rocks. Most of the contact types between granules of sandstone in the He- 8 and Shan-1 members were liner or point-liner contact (Figure 3(a)). As a result of high pressure and strong compaction, the brittle fracture of quartz particles and deformation of mica can often be observed in the thin sections. Plastic particles affected by compaction (e.g., mudstone debris and phyllite debris) underwent plastic deformation and formed a pseudomatrix. They filled the areas between particles or squeezed into pores, causing blockage.

The main types of cementation in the study area are siliceous cementation, authigenic clay minerals, and carbon- ate cementation. The main types of siliceous cementation are chalcedony and sedentary enlargement of quartz (Figures 3(b) and 3(c)). The authigenic clay minerals are dominated by minerals such as chlorite, montmorillonite, kaolinite, and illite. The carbonate cementation includes mainly calcite and iron calcite (Figures 3(d)-3(f)). The sections also reveal that calcite cementation was mainly formed after the sedentary enlargement of quartz. Cementation significantly reduced porosity and permeability of reservoir rocks in the block.

Replacement in the block is mainly a replacement of debris by carbonate and clay minerals. The replacement of feldspar, debris, and phyllite debris by chlorite and kaolinite may also be frequently observed (Figures 3(g) and 3(h)). It is also common to see reciprocal transformation of kaolinite to illite to chlorite and various species of carbonate minerals. In the early diagenetic stage, altered kaolinite helped develop a large number of intergranular pores. Thus, replacement plays an important role in the formation of reservoirs.

Dissolution in the study area created intergranular dissolved pores, interparticle dissolved pores, and moldic pores of feldspar and detritus (Figure 3(i)). This process occurred in an acid medium during the middle diagenetic stage and increased the porosity and permeability of reservoir rocks. Debris, matrix, and cement in reservoir rocks are easily dissolved in an acid environment. In general, the plastic interstitial fillings of the Su-54 block were dissolved to varying 


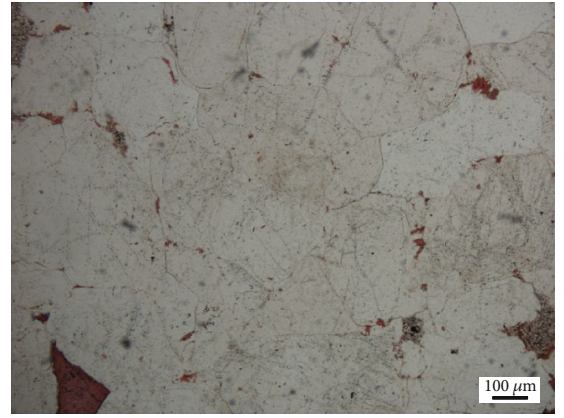

(a)

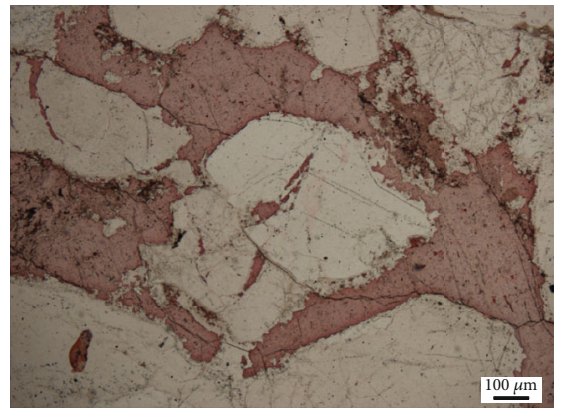

(d)

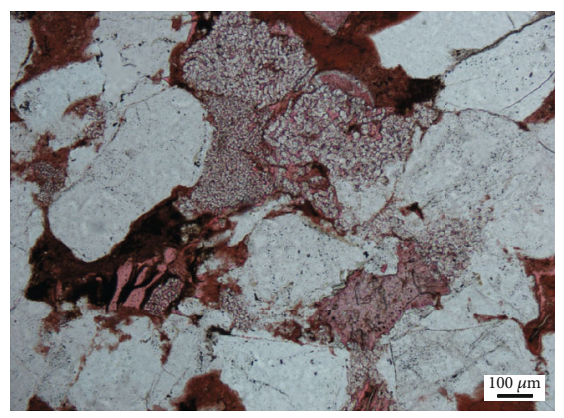

(g)

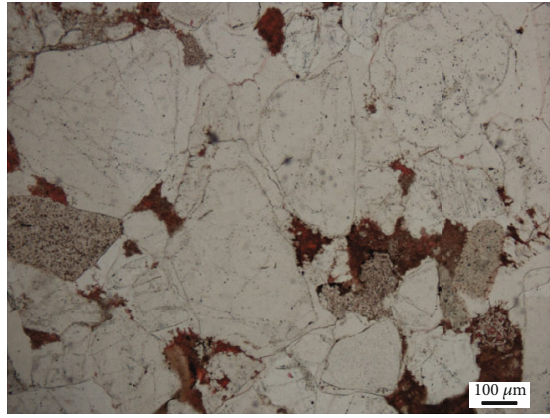

(b)

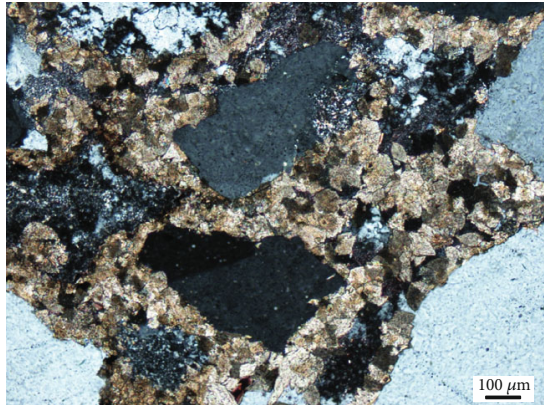

(e)

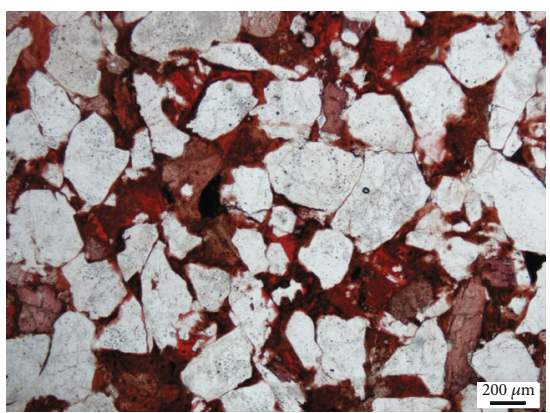

(h)

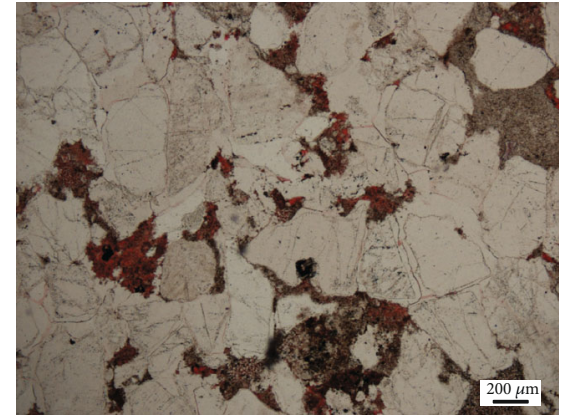

(c)

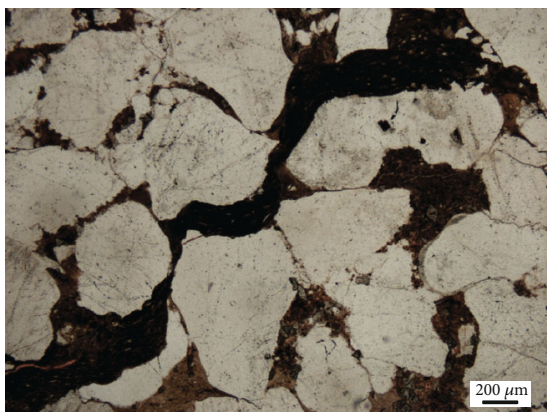

(f)

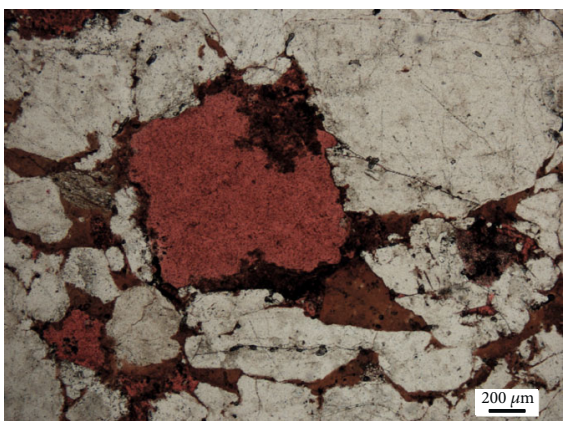

(i)

Figure 3: Main diagenesis types of the main gas interval in the western Sulige gas field. (a) Compaction and cementation (e18 Well, $3604.89 \mathrm{~m}$ ); (b) secondary enlargement of quartz (s146 Well, $3554.7 \mathrm{~m}$ ); (c) siliceous cementation (s245 Well, $3655.36 \mathrm{~m}$ ); (d) ferrocalcite (s245 Well, $3585.7 \mathrm{~m})$; (e) ferrodolomite cementation (e18 Well, $3697.17 \mathrm{~m}$ ); (f) ferruginous and argillaceous cementation (s68 Well, $3634.06 \mathrm{~m}$ ); (g) replacement of feldspar (s244 Well, $3552.61 \mathrm{~m}$ ); (h) intergranular dissolved pores (c1 Well,3515.85 m); (i) dissolved pore of detritus (s75 Well, $3432.27 \mathrm{~m}$ ).

degrees. It is common to observe the kaolinization of the argillaceous matrix. It is also not unusual to observe chlorite at the boundaries of dissolved particles and partially dissolved feldspar.

In general, the reservoir rock types in the area are mainly litharenite and lithic silicarenite. The reservoir rocks are characterized by a high content of quartz and lithic and low content of feldspar. They have an average porosity of $6.23 \%$ and an average permeability of $0.4 \mathrm{mD}$ [19], indicating lowporosity and low-permeability reservoirs. The diagenesis processes have strongly affected reservoir rocks in the Su-54 block. Among them, compaction is relatively strong due to the high burial depth. The process of compaction during the early digenetic stage destroyed most of the primary pores. In the later stage of diagenesis, dissolution helped create many secondary pores. The pore space is dominated by inter- granular dissolved pores and intercrystal pores which have survived the compaction [20].

\section{The Application of Gray Relational Analysis in Reservoir Evaluation}

Gray system theory was first proposed and constantly developed by Deng [10]. It is a mathematical method in factor association analysis mainly based on the mathematical foundations of space theory. In gray system theory, it is considered that although various factors are random and chaotic in a system, there are inevitable links between them. In this context, these are the reservoir parameters which are known as gray numbers in reservoir evaluation. As such, the relationship between these parameters may be studied, and the important factors influencing the target values may be 
identified to grasp the main features and provide a reliable basis for corresponding applications [13-15].

As the method is simple and convenient, it works with a wide range of different factors and only needs a relatively small amount of data and simple mathematical procedures to arrive at salient relationships within a complex system. As such, gray relational analysis has been introduced to many fields for analyzing discrete data series [30, 33-38].

4.1. Selection of Prediction Parameters. We combined the background information of the Su-54 block with gas testing data and core observation. This showed that when porosity is greater than $5 \%$, the penetration rate is greater than 0.06 $\times 10^{-3} \mu \mathrm{m}^{2}$, and gas saturation is generally greater than $50 \%$. As such, the reservoir has better gas measurement display. In the study area, a reservoir is considered to be effective when its permeability is greater than $0.1 \times 10^{-3} \mu \mathrm{m}^{2}$, porosity is greater than $5 \%$, and the gas saturation is greater than $50 \%$.

Indicators used to predict favorable gas areas include structural characteristics, sedimentary facies and microfacies, formation thickness, sandstone thickness, the ratio between sand thickness and stratigraphic thickness, the ratio of effective sand thickness and sand thickness, reservoir rock types and characteristics, diagenesis, porosity, permeability, saturation, and shale content. There is a gentle structure in the Su54 block; we do not need to consider the structural evaluation factors; therefore, high-quality reservoirs are controlled mainly by lithology factors. The Shan-1 $\left(\mathrm{P}_{1} s_{1}\right)$ and He-8 $\left(\mathrm{P}_{2}\right.$ sh $\left.\mathrm{h}_{8}\right)$ members are mainly fluvial reservoir sands. The effective He- 8 sand is located at the bottom of high-energy braid channels and central bars. The effective Shan-1 sand body is mainly located at central and point bars. Owing to their relatively simple lithology and facies, we did not use the lithology and lithological factors in the evaluation. In the exploration stage, we used the thickness of technically recoverable sands as the thickness of the effective sands. The sands found in most wells are only a small part of the whole sands. As most sands are not effective reservoirs because of their slightly lower flow capacity, the proportion of effective sands may be used to reflect the hydrocarbon potential of the well concerned. Therefore, the following parameters were selected to evaluate reservoirs in the study area: permeability $(K)$, porosity $(\Phi)$, effective sand thickness $(M)$, effective sand/sand thickness ratio $(D)$, and gas saturation $\left(S_{\mathrm{g}}\right)$.

Among the parameters, $K$ and $\Phi$ reflect the reservoir flow characteristics, $M$ indirectly represents the abundance and quantity of reserves, $D$ reflects the relative scale of the effective reservoir sands (indirectly representing the continuity of the effective sand body in the reservoirs), and $S_{\mathrm{g}}$ reflects the abundance of gas-bearing reservoirs. Usually, $K$ is closely linked to reservoir quality and is selected as a mother sequence. However, in our calculation, we used $M$ as the mother sequence as it is the actual testing data and thus more useful in subsequent production predictions. Favorable gas areas in the study block were finally forecasted based on combining calculations with analyses of the structure and sedimentary facies.
4.2. Prediction Methods. There are "segmented" limitations in traditional qualitative classification. As such, the forecast was undertaken by using a more quantitative approach under the control of the geological thinking application.

The equation describing the comprehensive evaluation index to quantitatively evaluate the reservoir is

$$
\mathrm{REI}=\sum_{i=1}^{n} a_{i} X_{i},
$$

where REI represents a comprehensive evaluation index. In Equation (1), " $n$ " is the number of the selected reservoir evaluation parameters, $X_{i}$ is the selected reservoir evaluation parameter, and $a_{i}$ is the weighting factor in the reservoir evaluation of each parameter. Both $n$ and $X_{i}$ are known parameters, and only the weighting factor $a_{i}$ is unknown. Thus, as long as the weighting factor is calculated, we can quantify the reservoir evaluation index.

Prior to using Equation (1) to evaluate reservoirs, the selected parameters need to be standardized and normalized as they are of different dimensions. We used a standardized method of the maximum value for each that was normalized. First, the maximum value of each parameter was selected. Then, the ratio of the maximum value of the individual parameter with similar parameters was used to represent the evaluation score so that each individual evaluation score was between zero and one. In general, the greater the parameter value, the better the reservoir properties. Parameters such as the effective thickness, porosity, and permeability were normalized directly by using the value of the parameter divided by the maximum value of its class parameters.

\subsection{The Process of Gray Relational Analysis}

4.3.1. Mother Sequence and Subsequence Selection. A mother sequence is a parameter index that plays a key role in referring to the quality of reservoirs evaluated. A subsequence plays a secondary role in assessing reservoir quality with the parameter index.

The focus of reservoir evaluation is often different during various stages of exploration and development. This is similar to the mother sequence evaluation parameters. The same sequence of evaluation parameters at different stages of oil and gas exploration and development has a different mother sequence.

To analyze reservoir characteristics, the relationship between factors, and their impact based on the internal structure data, we used a number of indicators to quantitatively describe the reservoir characteristics. These quantitative indicators are referred to as the mother sequence of correlation analysis (by [10, 13]; the following formulas are the same). It can be expressed as

$$
\left\{X_{t}^{(0)}(0)\right\}, \quad t=1,2, \cdots, n
$$

Subsequences are ordered arrays which affect the nature of various subfactors of reservoir data in reservoir 


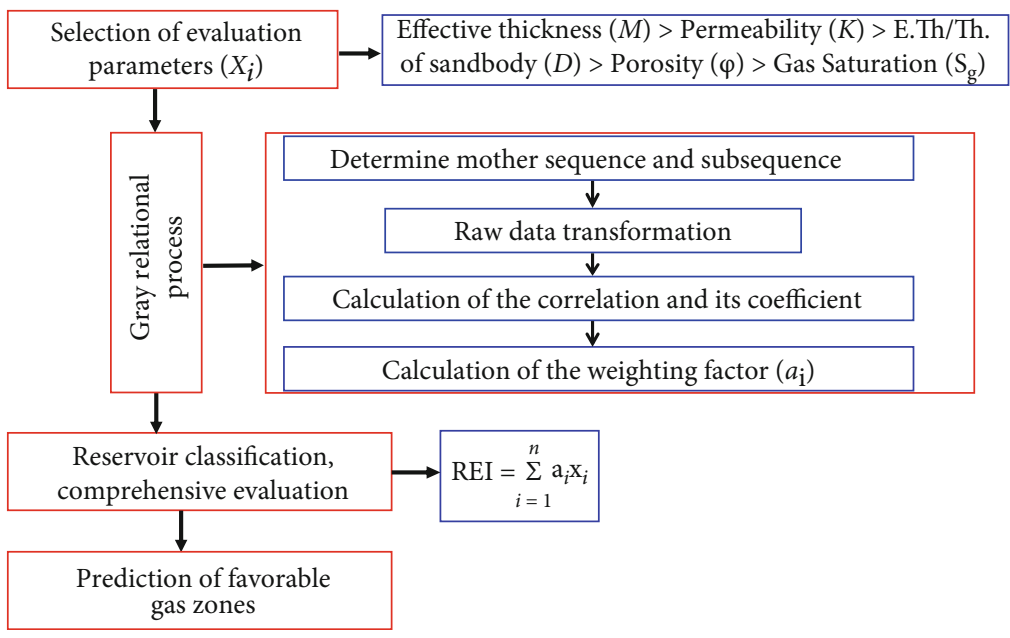

FIGURE 4: The brief process of gray relational analysis.

characteristics. Under normal circumstances, the main factors and subfactors require the same units or no units. In this case, the subsequence is denoted as

$$
\left\{X_{t}^{(0)}(i)\right\}, \quad i=1,2, \cdots, m, t=1,2, \cdots, n .
$$

4.3.2. Raw Data Transformation. Following the determination of mother sequences and subsequences, the raw data matrix may be constituted as

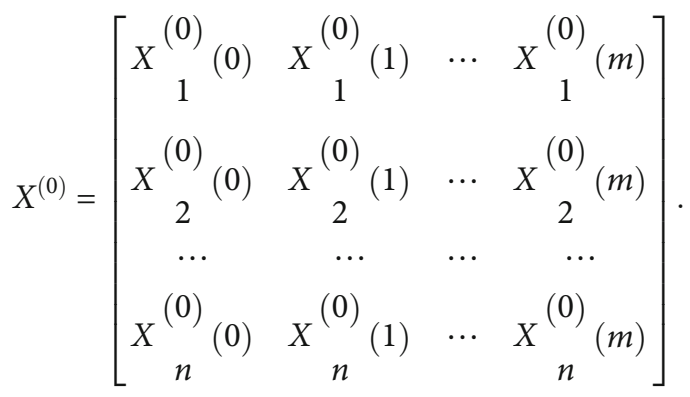

As the physical meaning of reservoir evaluation parameters is not identical, the dimensionless parameters are not necessarily the same. As such, it is necessary to eliminate the dimension of the processed original data and convert them into a comparable data series. Generally, we used the initialization and equalization method.

The initial value of the expression is

$$
X_{t}^{(1)}(i)=\frac{X_{t}^{(0)}(i)}{X_{1}^{(0)}(i)}
$$

In the formula, $i=1,2, \cdots, m, t=1,2, \cdots, n$.
The mean value of the expression is

$$
X_{t}^{(1)}(i)=\frac{X_{t}^{(0)}(i)}{\left[1 / n \sum_{t=1}^{n} X_{t}^{(0)}(i)\right]} .
$$

If the raw data is associated with the numerical comparison, it usually uses the equalization method. If a correlation analysis of dynamic sequences in a comparatively stable system is undertaken, it is usually transformed by initialization.

4.3.3. Calculation of the Correlation and Its Coefficient. Following the elimination of dimensions and data conversion, the mother sequence is $\left\{X_{t}^{(1)}(0)\right\}$, and $\left\{X_{t}^{(1)}(i)\right.$. $\}$ is the subsequence. The absolute difference and extremum between each subfactor and its main factor over a certain period or layer may be expressed as

$$
\begin{aligned}
& \Delta_{t}(i, 0)=\left|X_{t}^{(1)}(i)-X_{t}^{(1)}(0)\right|, \\
& \Delta \max =\max \max \left|X_{t}^{(1)}(i)-X_{t}^{(1)}(0)\right|, \\
& \Delta \min =\min \min \left|X_{t}^{(1)}{ }_{t}^{(i)-X_{(0)}^{(1)}}\right|,
\end{aligned}
$$

where $\Delta_{t}(i, 0)$ is the absolute difference of comparable intervals or sequences. Here, $\Delta \max$ and $\Delta \min$ are the absolute maximum and minimum differences of comparable sequences over all periods, respectively. As compared sequences intersect with each other, $\Delta \mathrm{min}$ is generally assumed to be zero. 
TABle 1: Parameters of wells in $\mathrm{P}_{2} s h \mathrm{~h}_{8}{ }^{2}$, the Su-54 block, western Sulige gas field.

\begin{tabular}{|c|c|c|c|c|c|}
\hline No. of well & $M(\mathrm{~m})$ & $D$ & $\Phi(\%)$ & $S_{\mathrm{g}}(\%)$ & $K(\mathrm{mD})$ \\
\hline $\mathrm{cl}$ & 1.05 & 0.05 & 14.73 & 54.63 & 4.38 \\
\hline e18 & 1.55 & 0.09 & 5.77 & 50.66 & 0.48 \\
\hline s101 & 13.63 & 0.56 & 10.23 & 31.40 & 0.74 \\
\hline s102 & 12.05 & 0.48 & 7.79 & 57.12 & 0.25 \\
\hline s104 & 6.38 & 0.20 & 6.15 & 48.20 & 0.36 \\
\hline s105 & 6.74 & 0.42 & 10.97 & 56.40 & 1.18 \\
\hline s106 & 4.01 & 0.19 & 8.43 & 40.93 & 0.64 \\
\hline s224 & 4.12 & 0.25 & 5.55 & 33.45 & 0.21 \\
\hline s229 & 9.76 & 0.37 & 9.55 & 44.73 & 0.36 \\
\hline s230 & 2.00 & 0.12 & 6.10 & 42.35 & 0.17 \\
\hline s245 & 2.00 & 0.08 & 6.71 & 39.28 & 0.21 \\
\hline s246 & 5.63 & 0.20 & 7.43 & 33.67 & 0.20 \\
\hline s247 & 6.13 & 0.21 & 10.18 & 39.95 & 0.44 \\
\hline s248 & 4.00 & 0.18 & 6.80 & 54.87 & 0.26 \\
\hline s330 & 3.75 & 0.17 & 7.06 & 31.85 & 0.46 \\
\hline s333 & 2.63 & 0.19 & 7.44 & 41.43 & 0.41 \\
\hline s371 & 4.00 & 0.26 & 10.78 & 46.83 & 0.54 \\
\hline s372 & 11.63 & 0.63 & 8.27 & 56.43 & 0.38 \\
\hline s373 & 11.51 & 0.51 & 9.75 & 54.10 & 0.59 \\
\hline s374 & 15.81 & 0.63 & 9.87 & 54.90 & 0.43 \\
\hline s376 & 8.13 & 0.40 & 10.42 & 55.34 & 0.44 \\
\hline s54 & 3.10 & 0.11 & 9.08 & 45.14 & 0.44 \\
\hline s57 & 3.20 & 0.20 & 6.60 & 55.48 & 0.23 \\
\hline s75 & 7.00 & 0.57 & 7.91 & 56.97 & 0.38 \\
\hline s83 & 3.89 & 0.22 & 9.86 & 45.50 & 0.71 \\
\hline e13 & 9.50 & 0.37 & 7.04 & 39.75 & 0.34 \\
\hline $\mathrm{e} 14$ & 7.87 & 0.16 & 14.05 & 46.05 & 1.64 \\
\hline e15 & 9.75 & 0.37 & 7.22 & 48.30 & 0.10 \\
\hline e21 & 1.13 & 0.05 & 4.22 & 42.36 & 0.27 \\
\hline e22 & 1.81 & 0.06 & 4.55 & 40.41 & 0.49 \\
\hline e23 & 1.56 & 0.05 & 7.19 & 45.55 & 0.15 \\
\hline e24 & 12.12 & 0.43 & 9.64 & 62.73 & 0.29 \\
\hline e25 & 8.38 & 0.25 & 5.40 & 43.83 & 0.33 \\
\hline $\mathrm{t} 1$ & 2.82 & 0.07 & 7.00 & 58.90 & 0.34 \\
\hline
\end{tabular}

The correlation coefficients of mother sequences and subsequences $L_{t}(i, 0)$ are generally expressed as

$$
\begin{aligned}
L_{t}(i, 0) & =\frac{\Delta \min +\rho \Delta \max }{\Delta_{t}(i, 0)+\rho \Delta \max }, \\
r_{i, 0} & =\frac{1}{n} \sum_{t=1}^{n} L_{t}(i, 0) .
\end{aligned}
$$

In Equation (8), $\rho$ is a distinguishing coefficient mainly used to weaken the absolute maximum difference should this value be very large. As such, to increase the difference between the correlation coefficients, $\rho \in(0,1)$. Here, under normal circumstances, this is assumed to be 0.5 for the more
TABLE 2: Weighted coefficients of the members in the Su- 54 block of the western Sulige gas field.

\begin{tabular}{lccccc}
\hline Member & $M$ & $D$ & $\Phi$ & $S_{\mathrm{g}}$ & $K$ \\
\hline $\mathrm{P}_{2} s h \mathrm{~h}_{8}{ }^{1}$ & 0.2156 & 0.2102 & 0.2064 & 0.1872 & 0.1806 \\
$\mathrm{P}_{2}{ }{ } \mathrm{~h}_{8}{ }^{2}$ & 0.2186 & 0.2075 & 0.1939 & 0.1937 & 0.1863 \\
$\mathrm{P}_{1} s_{1}$ & 0.2322 & 0.2238 & 0.2136 & 0.1644 & 0.1660 \\
\hline
\end{tabular}

TABle 3: Statistics of classification and evaluation of the reservoir stratum of members in the Su-54 block of the western Sulige gas field.

\begin{tabular}{lcccc}
\hline Member & $\begin{array}{c}\text { Total well } \\
\text { number }\end{array}$ & $\begin{array}{c}\text { Type } \\
\text { I/wells }\end{array}$ & $\begin{array}{c}\text { Type } \\
\text { II/wells }\end{array}$ & $\begin{array}{c}\text { Type } \\
\text { III/wells }\end{array}$ \\
\hline $\mathrm{P}_{2}$ shh $_{8}{ }^{1}$ & 10 & 0 & 3 & 7 \\
$\mathrm{P}_{2} \operatorname{shh}_{8}{ }^{2}$ & 29 & 15 & 9 & 5 \\
$\mathrm{P}_{1} s_{1}$ & 25 & 5 & 7 & 13 \\
\hline
\end{tabular}

TABLE 4: Reservoir types based on different comprehensive evaluation values in the study area.

\begin{tabular}{lccccc}
\hline Type & $\begin{array}{c}\text { Comprehensive } \\
\text { evaluation value }\end{array}$ & \multicolumn{4}{c}{$\begin{array}{c}\text { Percentages of different } \\
\text { types of reservoirs }\end{array}$} \\
\hline I & $>0.7$ & $\mathrm{P}_{2} s h \mathrm{~h}_{8}{ }^{1}$ & $\mathrm{P}_{2} s h \mathrm{~h}_{8}{ }^{2}$ & $\mathrm{P}_{2} s h \mathrm{~h}_{8}$ & $\mathrm{P}_{1} s_{1}$ \\
II & $0.5 \sim 0.7$ & $30.0 \%$ & $31.7 \%$ & $38.4 \%$ & $20.0 \%$ \\
III & $<0.5$ & $70.0 \%$ & $17.3 \%$ & $30.8 \%$ & $28.0 \%$ \\
\hline
\end{tabular}

significant difference between correlation coefficients. The correlation between each subfactor and its main factor is expressed as

$$
r_{i, 0}=\frac{1}{n} \sum_{t=1}^{n} L_{t}(i, 0)
$$

where $n$ represents the length of the sequence, that is, the number of data in each parameter. Thus, the correlation should be a limited number, generally ranging from 0.1 to 1 . The correlation value between the subfactors and main factors is closer to one, indicating a closer relationship between the subfactor and main factor. The stronger the association between the subfactors and main factors, the greater the impact of subfactors on the main factors. On the contrary, the smaller correlation values indicate a reduced impact of the subfactors on the main factors. After establishing a gray association in accordance with the following formula, we have the resulting value of the weight coefficient for each parameter in the reservoir evaluation:

$$
a_{i}=\frac{\gamma(i, 0)}{\sum_{i=1}^{n} \gamma(i, 0)}
$$

In the classification and evaluation of reservoirs, $K$ is one of the factors best reflecting the extent of reservoir merits ([9]; Zhang et al., 2008). This means the extent of the evaluated reservoir may be expressed by the available permeability. 
Table 5: Distribution patterns for various reservoir types in the Su-54 block of the western Sulige gas field.

\begin{tabular}{lccc}
\hline Member & Reservoir type I & Reservoir type II & Wells with favorable gas reservoirs \\
\hline $\mathrm{P}_{2} s h \mathrm{~h}_{8}{ }^{1}$ & None & Isolated or sporadic & $\mathrm{e} 13, \mathrm{~s} 333, \mathrm{e} 11$ \\
$\mathrm{P}_{2} s h \mathrm{~h}_{8}{ }^{2}$ & Isolated or concatenated & Concatenated & $\mathrm{s} 54, \mathrm{~s} 373, \mathrm{~s} 374, \mathrm{~s} 229, \mathrm{~s} 376, \mathrm{e} 11, \mathrm{~s} 101, \mathrm{~s} 372$, \\
$\mathrm{P}_{1} \mathrm{~s}_{1}$ & Isolated & Isolated or dendritic & $\mathrm{s} 331, \mathrm{~s} 105, \mathrm{e} 18, \mathrm{e} 13, \mathrm{e} 15, \mathrm{e} 24, \mathrm{~s} 247$ \\
\hline
\end{tabular}

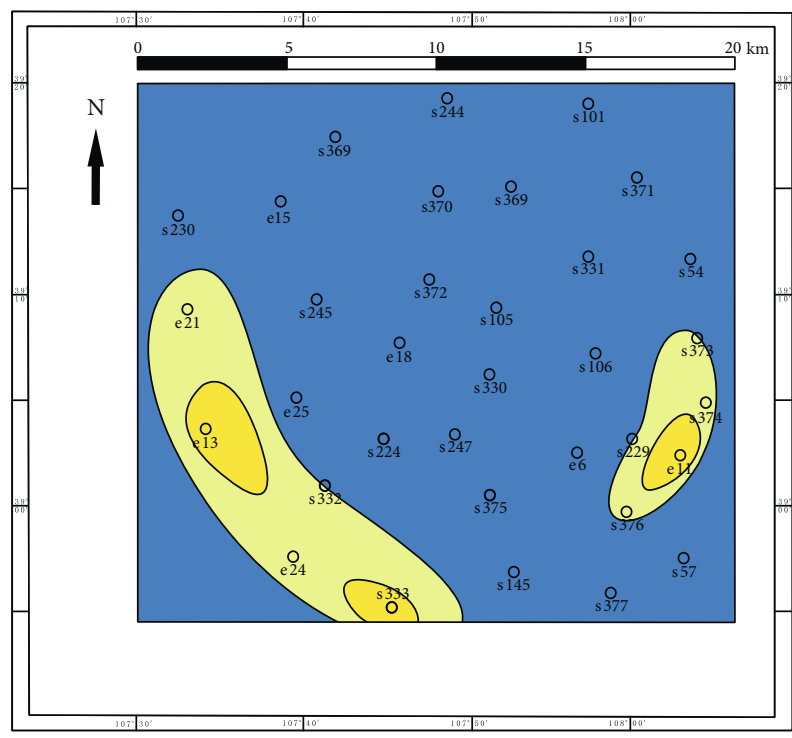

$\begin{array}{ll}\square & \text { Reservoir II } \\ \square & \text { Reservoir III } \\ \square & \begin{array}{l}\text { Non-essential } \\ \text { reservoir }\end{array}\end{array}$

(a)

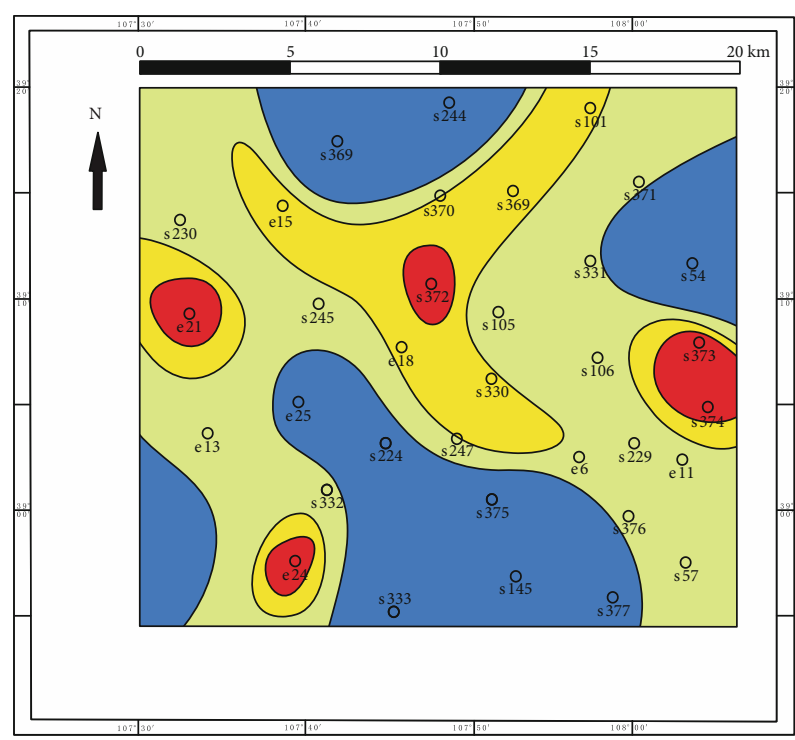

$\square$ Reservoir I

$\square$ Reservoir III

Non-essen
reservoir

(c)

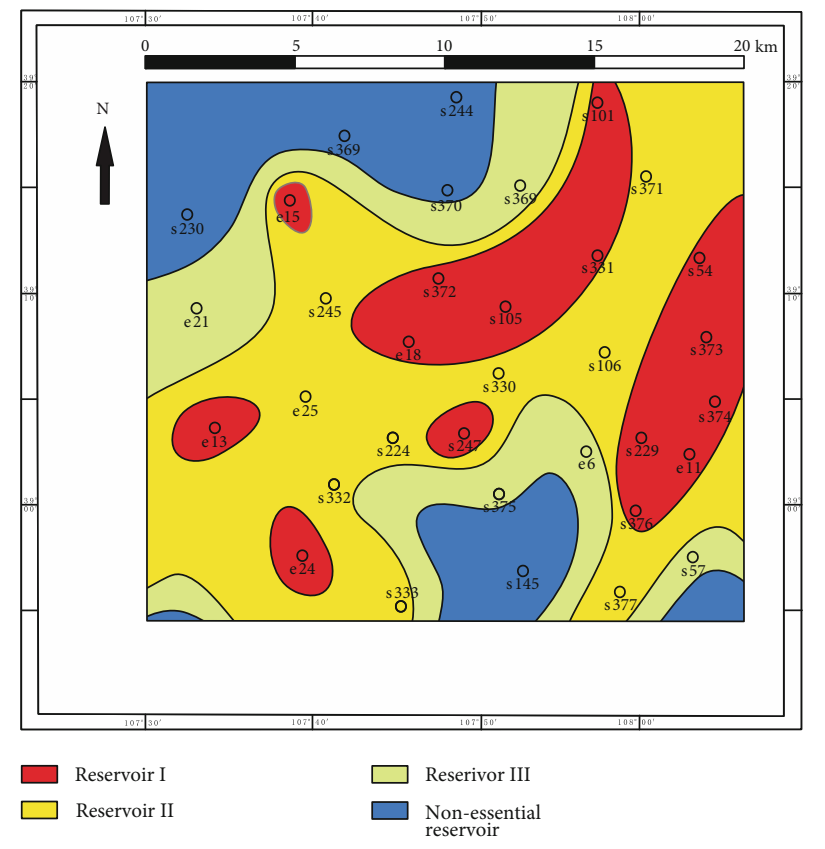

(b)

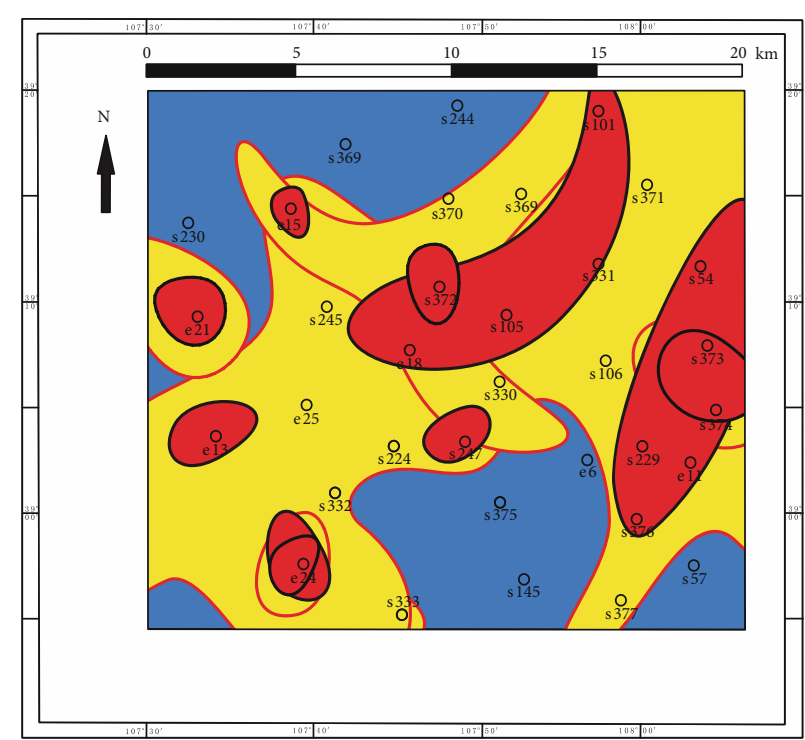

$\square$ Reserivor I
$\square$ Reservoir II

(d)

FIGURe 5: Prediction of favorable gas zones for $(\mathrm{a}) \mathrm{P}_{2} \operatorname{sh} \mathrm{h}_{8}{ }^{1}$, (b) $\mathrm{P}_{2} \operatorname{sh} \mathrm{h}_{8}{ }^{2}$, (c) $\mathrm{P}_{1} \mathrm{~s}_{1}$, and (d) superimposed layers in the Su-54 block of the western Sulige gas field. 
In addition, $\Phi, M, D$, and $S_{\mathrm{g}}$ from the other side represent the gas properties of the evaluated layer. The brief process of gray relational analysis is shown in Figure 4.

Table 1 presents the evaluation parameters for each well, using the data of $\mathrm{P}_{2} s h \mathrm{~h}_{8 \mathrm{x}}$ as an example.

Based on the gray relational analysis theory, we used $M$ as the mother sequence factor and other parameters as sequence factors. We calculated the correlation coefficient for each parameter at any level and then determined the parameters associated with each degree of effective thickness. The sequence associated with each segment was $M>K>D>\Phi$ $>S_{\mathrm{g}}$. Table 2 presents the weighted coefficients of the members following normalization.

These reservoir evaluation parameters and corresponding weights indicate the values of the main gas-bearing section and can be used to evaluate comprehensively the reservoir capacity of each well. Usually, the comprehensive evaluation value is equal or greater than 0.5 which means that the reservoir is more effective. In this case, we selected the value $\geq 0.7$ for type I reservoirs, $0.5-0.7$ for type II reservoirs, and $<0.5$ for type III reservoirs. Table 3 details the obtained and forecasted reservoir evaluation results of each section.

\section{Reservoir Prediction: Preliminary Forecasts of Favorable Gas Reservoir}

Table 4 presents the percentage of different reservoir types over all reservoirs in the members studied.

The table indicates that type I reservoirs are not well developed in the $\mathrm{P}_{2} s h \mathrm{~h}_{8}{ }^{1}$; the $\mathrm{P}_{2} s h \mathrm{~h}_{8}{ }^{2}$ is mainly dominated by type I and II reservoirs, accounting for $82.7 \%$ of the total. Type III reservoirs were a minor member, and $\mathrm{P}_{1} s_{1}$ had $48 \%$ of type I and II reservoirs and $52.0 \%$ of type III reservoirs.

On this basis, we performed a preliminary gas forecast for the study area. Table 5 shows that favorable gas areas distribute differently in various sections.

Overall, the $\mathrm{P}_{2} s h \mathrm{~h}_{8}{ }^{1}$ contains the least favorable gas areas, and the $\mathrm{P}_{2} s h \mathrm{~h}_{8}{ }^{2}$ had the most promising exploration target with its widely distributed and well-developed reservoirs (Figure 4). It can be seen that the gray correlation analysis method with improved parameter settings can better distinguish the types of reservoirs. Distribution of high-quality reservoirs not only is more in line with the development of sedimentary and sand body characteristics but also better matched with the existing geological understanding and exploration results. High-quality reservoirs of $\mathrm{P}_{2} s h \mathrm{~h}_{8}$ and $\mathrm{P}_{1} \mathrm{~s}_{1}$ in the study area are distributed along the direction of rivers to a certain extent. According to this sedimentary characteristic, type I reservoirs are mostly developed in point bars and central bars, so it is recommended that well blocks such as s372, s373, s374, and e24 could be future key development targets (Figure 5).

\section{Summary and Conclusions}

(1) In general, the reservoir rock types in the study area are mainly litharenite and lithic silicarenite. The rock has the low permeability and low porosity with clear evidence of strong diagenesis processes. Compaction is believed to be relatively strong due to great burial depth and destroy most of the primary pores. In a later stage of diagenesis, however, dissolution may contribute to creating secondary pores. This phenomenon may be responsible for the intergranular dissolved pores as the dominant pore type

(2) Our results show that the method of gray relational analysis requires a minimum amount of data and has a high accuracy and provides effective theoretical support for prediction. Using the process of (1) analysis of the normalized method, (2) selection of parameters including $M, D, \Phi, K$, and $S_{\mathrm{g}}$, and (3) the establishment of the mother sequence with $M$, we carried out original data transformation based on the principle of gray correlation. We calculated the correlation coefficient and correlation degree to determine an index weight in order to classify and comprehensively evaluate reservoirs in the study area

(3) Combined with the tectonic background, lithological features, diagenesis, and other sedimentary geological characteristics of the whole area, our prediction results showed that high-quality reservoirs $\left(\mathrm{P}_{2} s h \mathrm{~h}_{8}\right.$ and $\left.\mathrm{P}_{1} s_{1}\right)$ in the study area are distributed along the direction of rivers to a certain extent. Type I reservoirs are mostly developed in point bars and central bars. It is recommended that well blocks such as s372, s373, s374, and e24 could be future key development targets (Figure 5)

\author{
Abbreviations \\ K: $\quad$ Permeability \\ $\Phi: \quad$ Porosity \\ M: $\quad$ Effective sand thickness \\ $D: \quad$ Effective sand and sand thickness ratio \\ $S_{\mathrm{g}}: \quad$ Gas saturation \\ $\mathrm{P}_{1} \mathrm{~s}: \quad$ The Shanxi Formation of Lower Permian \\ $\mathrm{P}_{1} \mathrm{~s}_{1}$ : The first member of Shanxi Formation \\ (Shan-1 member) \\ $\mathrm{P}_{2}$ sh: $\quad$ The Shihezi Formation of Middle Permian \\ $\mathrm{P}_{2} \mathrm{shh}_{8}$ : $\quad$ The 8 th member of Shihezi Formation of \\ Middle Permian (He-8 member) \\ $\mathrm{P}_{2} \operatorname{shh}_{8}{ }^{1} / \mathrm{P}_{2} \operatorname{shh}_{8}{ }^{2}$ : The first/second interval of $\mathrm{P}_{2} \mathrm{shh}_{8}$.
}

\section{Data Availability}

The data used to support the findings of this study are available from the corresponding author upon request.

\section{Conflicts of Interest}

The authors declare that they have no conflicts of interest. 


\section{Acknowledgments}

This research was supported by the Chinese National Natural Science Foundation (Grant Nos. 42090020, 42090025, and 41811530094). We would like to thank the Changqing Oil Field Company for data support and core sampling.

\section{References}

[1] S. L. Jiang, L. L. Zhu, K. Y. Hong, and X. L. Hu, “Application of principal component analysis in shale gas favorable areas optimization," Journal of Geology, vol. 41, no. 2, pp. 251-256, 2017.

[2] X. F. Li, X. Z. Wang, Y. N. Xin, and R. Wang, "Effect of water distribution on methane adsorption capacity in shale clay," Chinese Journal of Theoretical and Applied Mechanics, vol. 48, no. 5, pp. 1217-1228, 2016.

[3] E. H. Liu, "The analysis on 2th member of Shan in Yanchang gas field by gray correlation method," Well Testing, vol. 2, pp. 18-20, 2014.

[4] Z. D. Zhan, H. Zhou, L. X. Guo, J. Zhu, and W. S. H. Huang, "The modeling and application of the key factors of controlling production of gas well based on gray correlation," Industrial Safety \& Environmental Protection, vol. 9, pp. 55-57, 2015.

[5] Z. X. Zhang, X. F. Kang, and F. F. Zhang, “Application of grey theory for oil and gas reservoir evaluation program optimization," Advanced Materials Research, vol. 616-618, pp. 10081012, 2012.

[6] X. Zhang, Q. B. Yan, and Z. B. Li, "Quantitative assessment of reservoirs in super-highly watered cut oil fields," Natural Gas Geoscience, vol. 1, no. 18, pp. 141-144, 2007, 148(in Chinese with English abstract).

[7] Q. Zhang and X. M. Zhu, "Quantitative assessment of clastic reservoir of the Paleogene Shahejie Formation in Dongying Sag of Shandong Province and its hydrocarbon significance," Journal of Palaeogeography, vol. 10, no. 5, pp. 455-472, 2008, (in Chinese with English abstract).

[8] J. M. Zhao, X. H. Chen, and Q. Zhang, "Application of grey association analysis in reservoir evaluation," Progress in Exploration Geophysics, vol. 26, no. 4, pp. 282-286, 2003, (in Chinese with English abstract).

[9] D. K. Zhong, C. J. Zhang, and Y. C. Wen, "Quantitative analysis method of factors affecting physical properties for sandstone reservoirs," Oil \& Gas Geology, vol. 21, no. 2, pp. 130132, 2000, (in Chinese with English abstract).

[10] J. Deng, "Control problems of grey system," System and Control Letters, vol. 1, no. 5, pp. 288-294, 1982.

[11] J. Deng, Grey Forcasting and Decision Making (in Chinese)., Huazhong University of Science and Technology Press, Wuhan, China, 1986.

[12] J. Deng, "Introduction to grey system theory," The Journal of Grey System, vol. 1, no. 1, pp. 1-24, 1989.

[13] J. Deng, Tutorial on Grey System Theory, Huazhong University of Science and Technology Press, Wuhan, China, 1990.

[14] Z. Mei, "Grey absolute correlation degree and its calculation method," Systems Engineering, vol. 10, no. 5, pp. 43-44, 1992.

[15] F. Y. Xu, X. S. Zhu, Q. B. Yan, and S. L. Li, “A method of determining the index weight in quantitative assessment of hydrocarbon-bearing characteristics in gas-bearing reservoir," Journal of Southwest-China Petroleum Institute, vol. 16, no. 4, pp. 11-17, 1994.
[16] J. H. Fu, X. S. Wei, and J. F. Ren, "Distribution and genesis of large-scale Upper Paleozoic lithologic gas reservoirs on YiShaan Slope," Petroleum Exploration and Development, vol. 35, no. 6, pp. 664-691, 2008.

[17] Q. Y. Liu, Z. J. Jin, Q. Q. Meng, X. X. Wu, and H. C. Jia, "Genetic types of natural gas and filling patterns in Daniudi gas field, Ordos Basin, China," Journal of Asian Earth Sciences, vol. 107, pp. 1-11, 2015.

[18] J. L. Liu, K. Y. Liu, and C. Liu, "Quantitative evaluation of gas generation from the Upper Paleozoic coal, mudstone and limestone source rocks in the Ordos Basin, China," Journal of Asian Earth Sciences, vol. 178, pp. 224-241, 2019.

[19] Q. B. Xie, J. Sun, J. P. Chen et al., "Model of the distribution of the polygenetic channel sand body of the Sulige large gas field," Earth Science Frontiers, vol. 20, no. 2, pp. 40-51, 2013.

[20] Q. B. Xie, X. Y. Tan, X. Gao, X. P. Liang, C. J. Lai, and Z. F. Wang, "Characteristics of the major gas-bearing reservoirs in western Sulige gas field," Lithologic Reservoirs, vol. 34, no. 7, pp. 27-33, 2014.

[21] H. Yang, J. H. Fu, X. S. Wei, and X. S. H. Liu, "Sulige field in the Ordos Basin: geological setting, field discovery and tight gas reservoirs," Marine and Petroleum Geology, vol. 25, no. 4-5, pp. 387-400, 2008.

[22] R. C. Yang, A. P. Fan, Z. Han, and X. P. Wang, "Diagenesis and porosity evolution of sandstone reservoirs in the East II part of Sulige gas field, Ordos Basin," International Journal of Mining Science and Technology, vol. 22, no. 3, pp. 311316, 2012.

[23] G. Y. Zhu, L. J. Gu, J. Su et al., "Sedimentary association of alternated mudstones and tight sandstones in China's oil and gas bearing basins and its natural gas accumulation," Journal of Asian Earth Sciences, vol. 50, pp. 88-104, 2012.

[24] Z. Q. Zhu, C. Y. Lin, S. J. Zhang et al., "Application of improved fuzzy-grey comprehensive evaluation method to quantitative reservoir evaluation: a case study of the lowpermeability gas reservoirs of the lower part of 8th member of the Shihezi Formation in Su X block of Sulige Gasfield," Oil \& Gas Geology, vol. 38, no. 1, pp. 197-208, 2017.

[25] F. Wang, H. D. Chen, J. X. Zhao, A. Q. Chen, Z. T. Su, and J. Li, "Sequence boundary and petroleum geology of the CambrianPermian strata in the Ordos Basin," Sedimentary Geology \& Tethyan Geology, vol. 31, no. 1, pp. 6-12, 2011.

[26] M. J. Liu, Z. H. Liu, W. Peng, and G. F. Pan, "Diagenesis of the Triassic Yanchang Formation tight sandstone reservoir in the Xifeng-Ansai area of Ordos Basin and its porosity evolution," Acta Geologica Sinica, vol. 90, no. 3, pp. 956-970, 2016.

[27] M. J. Liu, Y. Xiong, C. H. Xiong et al., "Evolution of diagenetic system and its controls on the reservoir quality of pre-salt dolostone: the case of the Lower Ordovician Majiagou Formation in the central Ordos Basin, China," Marine and Petroleum Geology, vol. 122, p. 104674, 2020.

[28] J. Dai, J. Li, X. Luo et al., "Stable carbon isotope compositions and source rock geochemistry of the giant gas accumulations in the Ordos Basin, China," Organic Geochemistry, vol. 36, no. 12, pp. 1617-1635, 2005.

[29] C. Jia, A. Jia, X. Zhao, J. Guo, and H. Tang, "Architecture and quantitative assessment of channeled clastic deposits, Shihezi sandstone (Lower Permian), Ordos Basin, China," Journal of Natural Gas Geoscience, vol. 2, no. 1, pp. 11-20, 2017.

[30] Y. Feng, B. Ji, and Y. Li, An Improved Grey Relation Analysis Method and Its Application in Dynamic Description for a 
Polymer Flooding Pilot of Xingshugang Field, Daqing, 2010, SPE 128510

[31] J. Z. Xu, Z. H. X. Chen, and R. Li, "Impacts of pore size distribution on gas injection in intraformational water zones in oil sands reservoirs," Oil \& Gas Science and Technology - Revue d'IFP Energies nouvelles, vol. 75, p. 75, 2020.

[32] M. J. Liu, G. Jon, W. B. Wang et al., "Tight oil sandstones in Upper Triassic Yanchang Formation, Ordos Basin, N. China: reservoir quality destruction in a closed diagenetic system," Gelogical Journal, vol. 54, no. 6, pp. 3239-3256, 2018.

[33] C. M. Lee, "Grey system theory with application to earthquake forecasting," Journal of Seismology, vol. 4, pp. 27-31, 1986.

[34] C. G. Lin, "Application of grey system theory to gas pool prediction of 3D seismic data prior to drilling," in SPE Asia Pacific Oil and Gas Conference and Exhibition, Jakarta, Indonesia, April 1999.

[35] P. Li, T. C. Tan, and J. Y. Lee, "Grey relational analysis of amine inhibition of mild steel corrosion in acids," Corrosion, vol. 53, no. 3, pp. 186-194, 1997.

[36] H. Y. Li, "Study on the calculation method of grey relationship degree," Systems Engineering \& Electronics, vol. 26, no. 9, pp. 1231-1233, 2004.

[37] D. Y. Qi, Y. G. Hu, and F. C. Xiao, "Fuzzy-grey-element relational decision-making analysis \& its application," in SPE India Oil and Gas Conference and Exhibition, New Delhi, India, February 1998.

[38] X. R. Tan, Y. G. Li, and M. Z. Chen, "Applications of gray relational analysis in gastroenterology," World Journal of Gastroenterology, vol. 11, no. 22, pp. 3457-3460, 2005. 